\title{
Evolution of the obscura group Drosophila species. III. Phylogenetic relationships in the subobscura cluster based on homologies of chromosome A
}
A. Brehm and
C. B. Krimbas

Department of Genetics, Agricultural University of Athens, Greece.

The Drosophila subobscura cluster comprises $D$. subobscura, D. madeirensis and $D$. guanche, species closely related so some interspecific crosses are possible. This paper clarifies definitively the homologies of the segments of the sex chromosome $A(=X)$ among these species and thus permits a phylogenetic seriation of them. This seriation is identical to the one suggested by the study of chromosome $O$ and concordant with similar data for the remaining three rod autosomes $(J, U$ and $E$ ), which, however, do not provide qualitative evidence on this subject.

\section{INTRODUCTION}

Trees, revealing the phylogenetic relationships among species, depict the historical dimension of their evolutionary process, especially cladogenesis, but are very poor indicators of the evolutionary mechanisms. Molecular techniques provide a powerful tool for inferring phylogenetic relationships. In certain cases, however, more classical approaches are as, if not more, powerful: the identification of homologies of chromosomal segments among closely related species. The three species belonging to the subobscura cluster of species of the obscura group of the genus Drosophila, namely $D$. subobscura, D. madeirensis and D. guanche, constitute such a case.

From crosses between $D$. madeirensis and $D$. subobscura, and between $D$. madeirensis and $D$. guanche, Krimbas and Loukas (1984) were able to establish the following gene arrangements for $D$. madeirensis and $D$. guanche in relation to the standard sequence of $D$. subobscura:

$$
\begin{array}{ll}
\text { D. madeirensis: } & \mathrm{A}_{16 \mathrm{BCD}+1} ; \mathrm{J}_{\mathrm{ST}} ; \mathrm{E}_{\mathrm{ST}} ; \mathrm{U}_{1+2} ; \mathrm{O}_{3} \\
\text { D. guanche: } & \mathrm{A}_{16 \mathrm{BCD}+\mathrm{ga}} ; \mathrm{J}_{\mathrm{gb}} ; \mathrm{E}_{\mathrm{gc}} ; \mathrm{U}_{1+2} ; \mathrm{O}_{3+\mathrm{gd}}
\end{array}
$$

where ST indicates the standard sequence of $D$. subobscura and numbers and letters symbolize inversions, while the plus sign indicates the presence of more than one inversion on that chromosome. Inversions $\mathrm{A}_{1}, \mathrm{U}_{1+2}, \mathrm{O}_{3}$ are inversions already known from the study of the chromosomal polymorphism of $D$. subobscura, whereas $A_{16 \mathrm{BCD}}$ was a new small distal inversion on the sex chromosome fixed in the other two species, and $\mathrm{A}_{\mathrm{ga}}, \mathrm{J}_{\mathrm{gb}}, \mathrm{E}_{\mathrm{gc}}, \mathrm{O}_{\mathrm{gd}}$ were inversions specific to $D$. guanche.

The case of chromosome $\mathrm{O}$ is of special interest: in $D$. subobscura inversion $\mathrm{O}_{3}$ is never found alone but only in combination with the overlapping inversion $\mathrm{O}_{4}$, thus forming the arrangement $\mathrm{O}_{3+4}$. From this arrangement other ones are derived. On the other hand, in D. subobscura the standard gene arrangement of chromosome $\mathrm{O}$ is present and this arrangement lacks $\mathrm{O}_{3}$. The postulated existence of a gene arrangement having $\mathrm{O}_{3}$ alone, as an intermediate step required between $\mathrm{O}_{3+4}$ and $\mathrm{O}_{\mathrm{ST}}$, was confirmed from the study of the two other species of this cluster, where $\mathrm{O}_{3}$ was found without its accompanying inversion $\mathrm{O}_{4}$. In $D$. guanche another inversion, overlapping $\mathrm{O}_{3}$, was observed, $\mathrm{O}_{\mathrm{gd}}$, thus permitting the establishment of the following seriation of gene arrangements (and eventually of the species carrying them):<smiles></smiles>

or D. subobscura-D. madeirensis-D. guanche. Of course this seriation of species is based on the further assumption that no transpecific poly- 
morphism existed and fixation of an inversion within the phylogeny was a unique event.

Chromosome A of D. guanche was found fixed for the small distal inversion 16BCD and for a medial one including sections 9-14 (according to the map of Kunze-Muhl and Muller 1958), but otherwise following the standard gene sequence. Later, Molto and Martinez-Sebastian (1986) confirmed the presence of inversion $16 \mathrm{BCD}$ in $D$. guanche but corrected the break points of the second inversion as $10 \mathrm{C}-134 \mathrm{~A} / \mathrm{B}$. They also found that the proximal part of the chromosome did not bear the standard sequence of $D$. subobscura but probably carried inversion $A_{1}$ and several others superimposed on it. Thus the proximal part of chromosome A remained unhomologized. A year later, Molto et al. (1987) reported in detail their interpretation. They presented photomaps of $\mathrm{A}$ chromosome for both $D$. subobscura and $D$. guanche and also indicated the correspondence of different sections to the map of Kunze-Muhl and Muller. They basically confirmed their previous interpretation with some minor differences in break points. They remarked, however, that the proximal segment of this chromosome is so different in these two species that homologies could not be established with certainty. They have proposed a hypothetical phylogeny of these gene arrangements assuming that inversion $A_{1}$ was involved. Four inversions were needed to make the transition between the two species for the proximal part of the chromosome and two more for the remaining part, six in total. For the remaining chromosomes Molto et al. corrected the position of some break points given by Krimbas and Loukas (1984) and Felger (1985, in Molto et al. 1987).

The purpose of the present paper is to correct Molto et al.'s interpretation and establish an accurate homology among the different regions of the A chromosome of the species of the subobscura cluster and thus provide a firm ground for inferring phylogenetic relationships for these species.

\section{MATERIALS AND METHODS}

Two strains, one from Kusnacht, monomorphic for the standard gene arrangements in all its chromosomes, and one from Finland, carrying inversion $A_{1}$, were used for $D$. subobscura. No chromosomal polymorphism has been found up till now in $D$. madeirensis and $D$. guanche, so one strain for each of them was used. Photomaps of chromosome A, from salivary glands of very early pupae, were used for comparing these species as well as photographs of hybrids between $D$. madeirensis and D. subobscura.

\section{RESULTS}

The only possible interspecific crosses are the following (Krimbas and Loukas 1984, Khadem and Krimbas unpublished):

\section{\& D. madeirensis $\times ð$ D. subobscura \\ 으. subobscura $\times \delta^{*} D$. madeirensis}

and

\section{\& D. madeirensis $\times \delta$ D. guanche.}

The first two crosses produce sterile males but fertile female $F_{1}$ hybrids, while the third produces both female and male sterile hybrids. In order to establish that $D$. madeirensis shares the same $A_{1}$ inversion with $D$. subobscura a cross was made between $D$. madeirensis and the strain from Finland of $D$. subobscura carrying the $A_{1}$ inversion. Hybrid females, heterozygotes for subobscura's $A_{1}$ and madeirensis chromosome $\mathrm{A}$ were studied. It was found that the two inversions, $A_{1}$ and that carried by $D$. madeirensis, from now on designed as $A_{1 M A D}$, slightly differ in their break points, see fig. 1. The consequences of the mistaken identification of $A_{1}$ with $A_{1 M A D}$ are obvious: they direc-

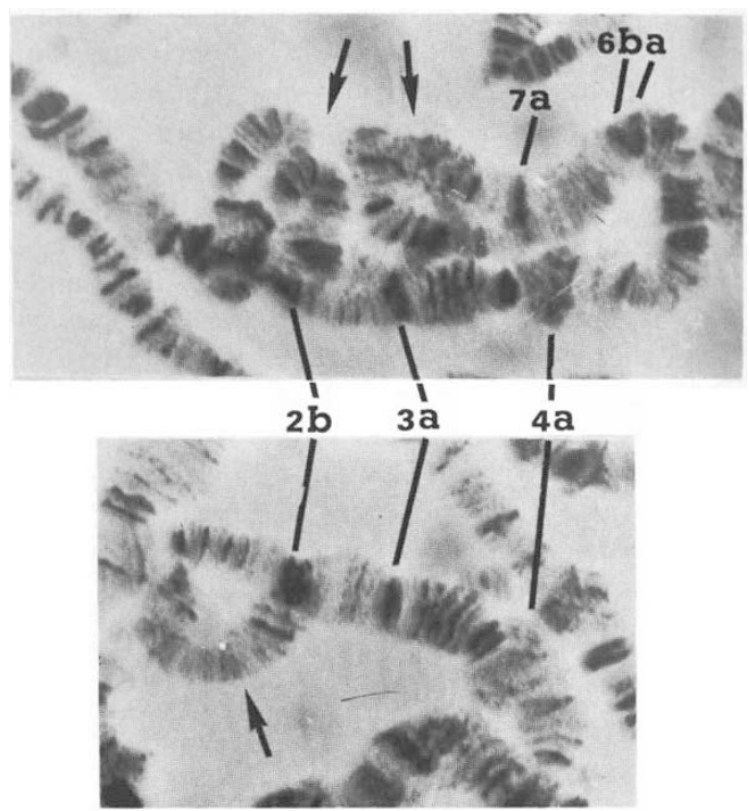

Figure 1 Chromosomes A of a hybrid female ( $D$. madeirensis $\times$ D. subobscura) heterozygote for $\mathrm{A}_{1 \mathrm{MAD}} / \mathrm{A}_{1}$. 


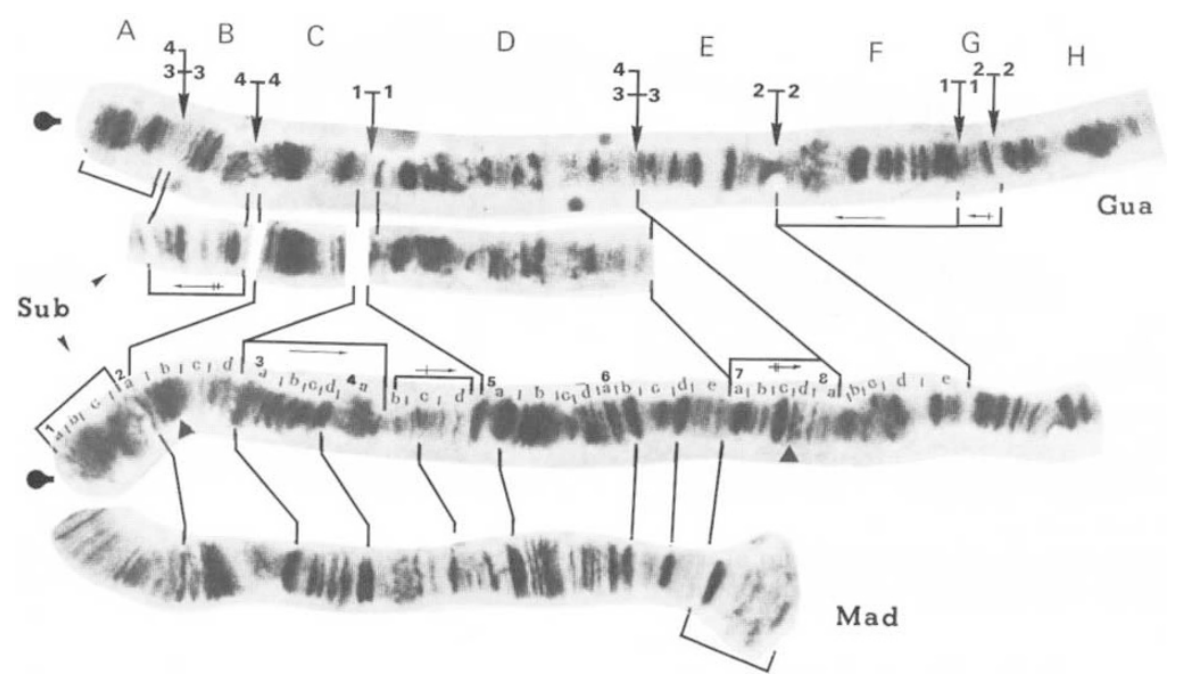

Figure 2 Homologies of the proximal part of chromosome A for the three species studied. The standard gene arrangement of $D$. subobscura (SUB) is displayed divided in sections according to the map of Kunze-Muhl and Muller. Solid triangles indicate the break points of inversion $A_{1}$. On the gene arrangement of $D$. guanche (GUA) are indicated the break points of four inversions, 1 (different from $D$. subobscura $A_{1}$ ) to 4 , which permit the transition of this gene arrangement to that of the other species. Thus $\mathrm{GUA}_{1+2+3}$ is the sequence of $D$. madeirensis (MAD) and GUA $1+2+3+4$ that of $D$. subobscura's ST arrangement. Letters A to $\mathrm{H}$ define the five segments mentioned in the text, while a solid circle with a bar indicates the position of the centromere.

ted Molto et al. (1987) to an erroneous phylogeny. As shown in fig. 2, where photographs of the proximal part of the A chromosomes are shown for the three species in question, the proximal part can be subdivided in 8 regions, denoted by the capital letters A to $\mathrm{H}$, having in $D$. guanche the following order: A B C D E F G $\mathrm{H}$. The corresponding order in the standard sequence of $D$. subobscura is:

$$
\begin{array}{lllllllll}
\text { A } & C & F^{\leftarrow} & G^{\leftarrow} & \text { D } & B^{\leftarrow} & \text { E } & H
\end{array}
$$

and that of $D$. madeirensis:

$$
\begin{array}{lllllllll}
\text { A } & D^{\leftarrow} & \text { G } & \text { F } & \mathrm{C}^{\leftarrow} & \mathrm{B}^{\leftarrow} & \mathrm{E} & \mathrm{H} & \text {. }
\end{array}
$$

By an arrow positioned after the region we indicate that this region is inverted in comparison to that of $D$. guanche. The break points are indicated in this figure as well as in fig. 7, which reproduces one of the four possible sequences which permits the transition from the guanche to the subobscura gene arrangement. These four possible sequences are the only possible sequences of a minimum number of paths, that is to say of a minimum number of inversions needed for making the transition from one to the other gene arrangement. This minimum number of inversions needed for the transition from the guanche to the subobscura gene arrangement is four. It may be found by repeated hand trials. Fig. 2 includes also a photomap of the proximal part of the A chromosome with the indi- cations of the corresponding numbered sections of the map drawn by Kunze-Muhl and Muller (1958).

The remaining part of the $\mathrm{A}$ chromosome (medial and distal) is depicted in the photographs of fig. 3. It contains a partial photomap of the subobscura standard sequence as well as the madeirensis and guanche sequences. This last species differs from the other two by an inversion comprising the segments $10 \mathrm{C}$ to $13 \mathrm{~A} / \mathrm{B}$ (the locations of the break points are the same as those mentioned by Molto et al. 1987). Both $D$. madeirensis and $D$. guanche differ from $D$. subobscura by the small distal inversion $16 \mathrm{BCD}$, considered as a terminal one. A careful study of photomaps and of several photographs of hybrids between $D$. madeirensis and $D$. subobscura revealed that the two last bands of the terminal subsection $16 \mathrm{D}$ are not included within this inversion, by which $D$. guanche and $D$. madeirensis differ from $D$. subobscura (fig. 4). In fig. 5 we summarize, in a drawing, the homologies among the three species for all the segments of chromosome A.

\section{DISCUSSION}

It is now possible to attempt the establishment of the phylogenetic relationships of the three species 


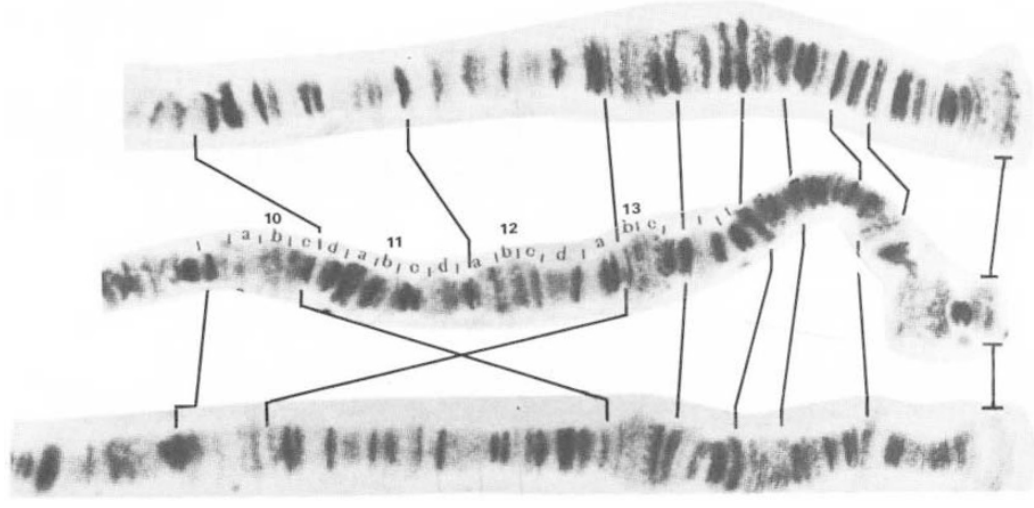

Figure 3 Homologies of the distal and medial part of chromosome A among the three species of the subobscura cluster. Inversion $10 \mathrm{C}-13 \mathrm{~A}$ is typical of $D$. guanche gene arrangement.
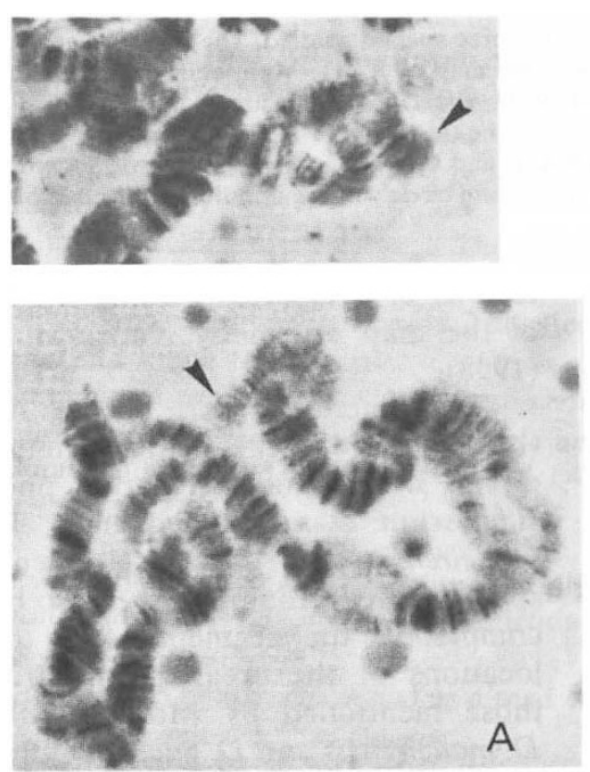

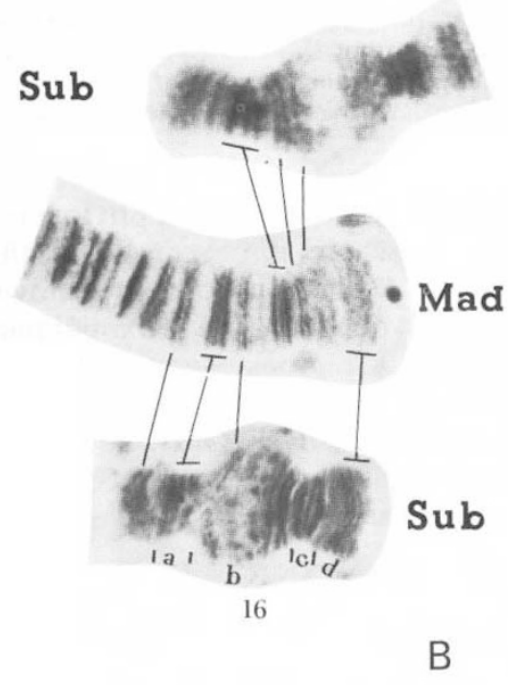

Figure 4 The distal terminal part of chromosome A of female hybrids ( $D$. madeirensis $\times D$. subobscura) heterozygotes for inversion $16 \mathrm{BCD}$. Arrows indicate the non-pairing parts of subsection $16 \mathrm{D}$, which is not included in the inversion.

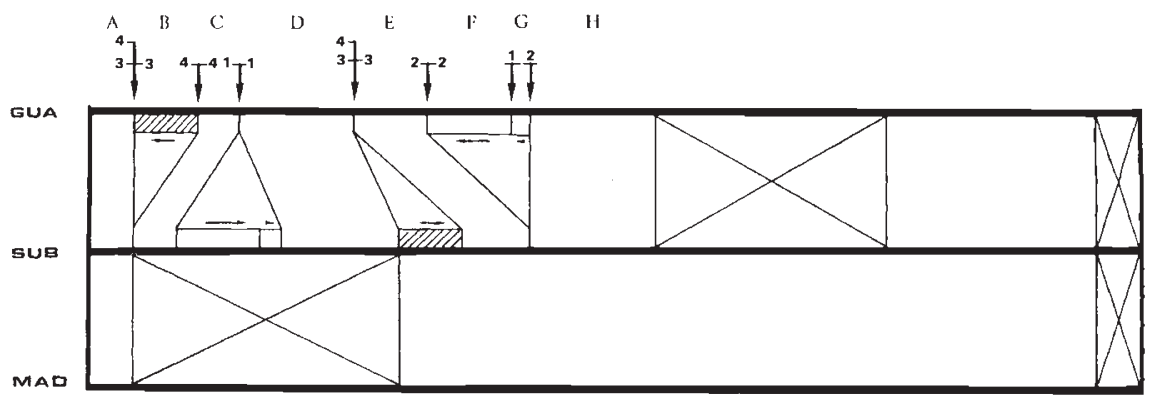

Figure 5 Diagram showing chromosome A homologies. The seriation of the species does nos not indicate phylogenetic relationships. 


\begin{tabular}{|c|c|c|c|c|c|c|c|c|}
\hline 1st & GUANCHE & A & B & $\mathrm{C}$ & $\mathrm{D}$ & $\mathrm{E}$ & $\mathbf{F}$ & G \\
\hline & & A & B & $\mathrm{D}^{-}$ & $\mathrm{C}^{+}$ & $\mathrm{E}$ & $\mathrm{F}$ & G \\
\hline & & A & $\mathrm{C}$ & $\mathrm{D}$ & $\mathrm{B}^{-}$ & $\mathrm{E}$ & $\mathrm{F}$ & G \\
\hline & & A & $\mathrm{C}$ & $\mathrm{F}^{*}$ & $\mathrm{E}^{+}$ & $\mathrm{B}$ & $\mathrm{D}^{-}$ & G \\
\hline & SUBOBSCURA & A & $\mathrm{C}$ & $\mathrm{F}^{*}$ & $\mathrm{G}^{+}$ & $\mathrm{D}$ & $\mathrm{B}^{+}$ & $\mathrm{E}$ \\
\hline 2nd & GUANCHE & A & B & $\mathrm{C}$ & $\mathrm{D}$ & $\mathrm{E}$ & $\mathrm{F}$ & G \\
\hline & & A & $\mathrm{D}^{+}$ & $\mathrm{C}^{+}$ & $\mathrm{B}^{+}$ & $\mathrm{E}$ & $F$ & G \\
\hline & & A & $\mathrm{C}$ & $\mathrm{D}$ & $\mathrm{B}^{+}$ & $E$ & $\mathbf{F}$ & G \\
\hline & & A & $\mathrm{C}$ & $\mathrm{F}^{+}$ & $\mathrm{E}^{+}$ & $\mathrm{B}$ & $\mathrm{D}^{+}$ & $\mathrm{G}$ \\
\hline & SUBOBSCURA & A & $\mathrm{C}$ & $\mathrm{F}^{\leftarrow}$ & $\mathrm{G}^{+}$ & $\mathrm{D}$ & $\mathrm{B}^{-}$ & $\mathrm{E}$ \\
\hline $3 \mathrm{rd}$ & GUANCHE & A & B & $\mathrm{C}$ & $\mathrm{D}$ & $\mathrm{E}$ & $\mathbf{F}$ & G \\
\hline & & A & B & $\mathrm{C}$ & $F^{\leftarrow}$ & $E^{-}$ & $\mathrm{D}^{-}$ & G \\
\hline & & A & B & $\mathrm{C}$ & $\mathrm{F}^{-}$ & $\mathrm{G}^{+}$ & $\mathrm{D}$ & $\mathrm{E}$ \\
\hline & & A & $\mathrm{B}$ & $\mathrm{D}^{-}$ & $G$ & $F$ & $\mathrm{C}^{\leftarrow}$ & $\mathrm{E}$ \\
\hline & SUBOBSCURA & A & $\mathrm{C}$ & $\mathrm{F}^{\leftarrow}$ & $\mathrm{G}^{+}$ & $\mathrm{D}$ & $\mathrm{B}^{-}$ & $\mathrm{E}$ \\
\hline 4th & GUANCHE & A & B & $\mathrm{C}$ & $\mathrm{D}$ & $\mathrm{E}$ & $\mathbf{F}$ & G \\
\hline & & A & B & $\mathrm{C}$ & $F^{-}$ & $\mathrm{E}^{-}$ & $\mathrm{D}^{-}$ & $\mathrm{G}$ \\
\hline & & A & B & $\mathrm{C}$ & $\mathrm{F}^{-}$ & $\mathrm{G}^{\leftarrow}$ & D & $\mathrm{E}$ \\
\hline & MADEIRENSIS & A & $\mathrm{D}^{+}$ & $\mathrm{G}$ & $\mathbf{F}$ & $\mathrm{C}^{\leftarrow}$ & $\mathrm{B}^{-}$ & $\mathrm{E}$ \\
\hline & SUBOBSCURA & A & $\mathrm{C}$ & $F^{\leftarrow}$ & $\mathrm{G}^{*}$ & $\mathrm{D}$ & $\mathrm{B}^{-}$ & $\mathrm{E}$ \\
\hline
\end{tabular}

Figure 6 The four possible sequences for the transition of the guanche to the subobscura gene arrangements using a minimal number of inversions.

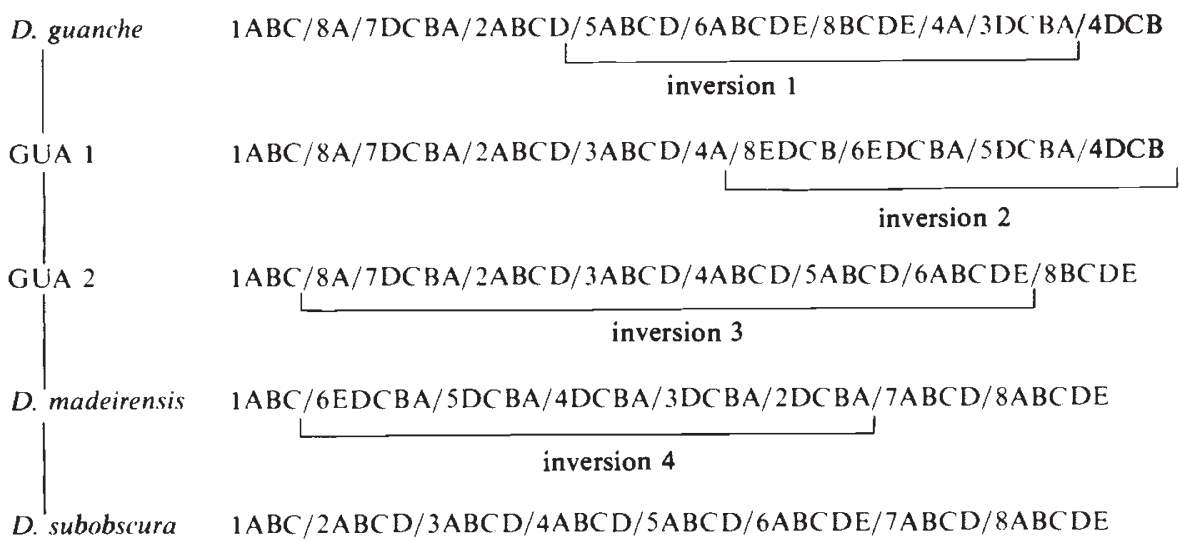

Figure 7 The most probable sequence of events, which permitted the transformation of the gene arrangement of $D$. guanche to the standard sequence of $D$. subobscura. $\mathrm{GUA}_{1}$ and $\mathrm{GUA}_{2}$ are hypothetical gene sequences. 


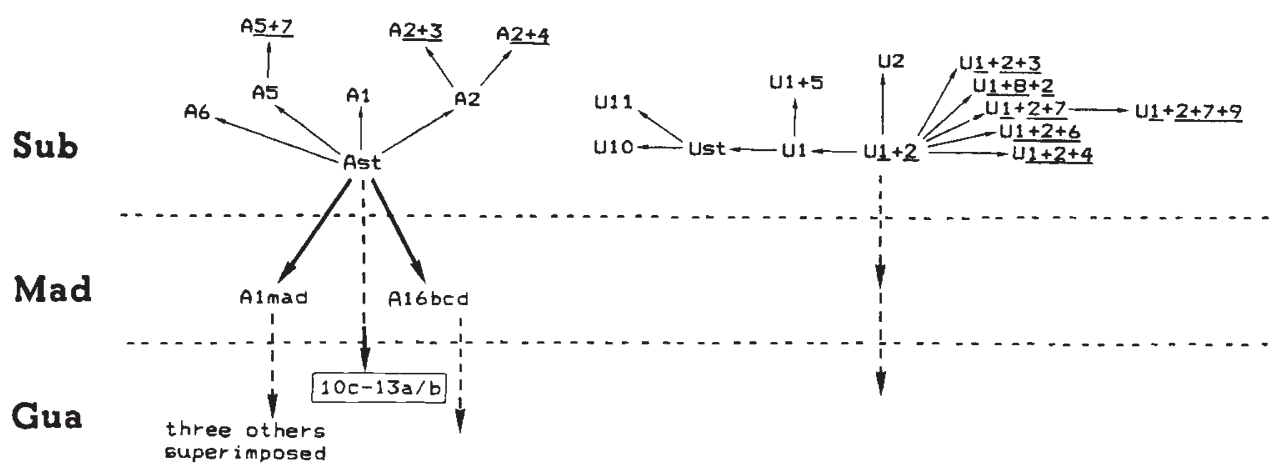

Figure 8 Phylogenetic seriation of the three species suggested by chromosome $A$ is concordant with the

of the subobscura cluster using the data presented previously regarding the homologies of the regions of their respective A chromosomes. The standard gene arrangement of chromosome $\mathrm{A}$ of $D$. subobscura (the most convenient to use for this purpose, since it seems to be the closer one to that of the other two species) differs from the sequence of $D$. madeirensis by one subterminal inversion, $16 \mathrm{BCD}$, and by another starting near the proximal end, $A_{1 M A D}$, which is different in its break points from $A_{1}$ of $D$. subobscura (instead of $2 \mathrm{~A} / \mathrm{B}-7$ $\mathrm{C} / \mathrm{D}$ or rather $7 \mathrm{D} / 8 \mathrm{~A}$ as corrected by Jungen 1968 for $A_{1}$ ).

D. guanche is fixed for the same small subterminal inversion $16 \mathrm{BCD}$, also for a second one, specific to this species, $A_{\text {ga }}$ (with break points $10 \mathrm{C}$ to $13 \mathrm{~A} / \mathrm{B}$ ), and for a complicated rearrangement of the proximal part of the A chromosome. This rearrangement can be derived from the standard sequence of $D$. subobscura by a series of four overlapping inversions, and from the sequence of $D$. madeirensis by three successive overlapping inversions.

There are, as previously mentioned, four different pathways to derive the A gene arrangement of $D$. guanche from the standard gene arrangement of $D$. subobscura; these are shown in fig. 6 which uses the same symbolism as above). For every of these "minimal number of inversions" pathways we have indicated the intermediate hypothetical sequences derived by each consecutive inversion (segments to be inverted have been indicated in boxes). Which one of these four pathways was actually followed during the evolution of these species? The most economical explanation indicates the fourth sequence of events, since the third intermediate step in this sequence depicts the gene arrangement of $D$. madeirensis: in this case we have an extant intermediate sequence present in another species of this cluster (fig. 7). This sequence of events points to the following phylogenetic relations of these species:

D. guanche-D. madeirensis - D. subobscura.

In this seriation the older species, the root of the tree, cannot be established but it was possible to figure it out when outgroups were used: in a study of the homologies of autosomes of nine species of the obscura group, including the species of the subobscura cluster, it was found that $D$. guanche is closer to $D$. subsilvestris and $D$. obscura and by them to the remaining species (Brehm and Krimbas, in preparation).

It may seem somewhat odd to position phylogenetically extant species in a row instead of using a tree structure; undoubtedly in theory a tree topology describes better the evolutionary development, however, the most parsimonious description in our case suggests that for chromosome A evolution, some of the tree branches have a zero length, collapsing the tree to a linear seriation. The method of inference of phylogenetic relations we used, presupposes several assumptions. For drawing phylogenetic relations between gene arrangements we have followed the method of overlapping inversions of Sturtevant and Dobzhansky (1936) which assumes that inversions have a unique occurrence and are produced successively. A phylogeny of gene arrangements may depict that of the species bearing these arrangements if there is no introgression, and, as stated before, if there is no transpecific retention 


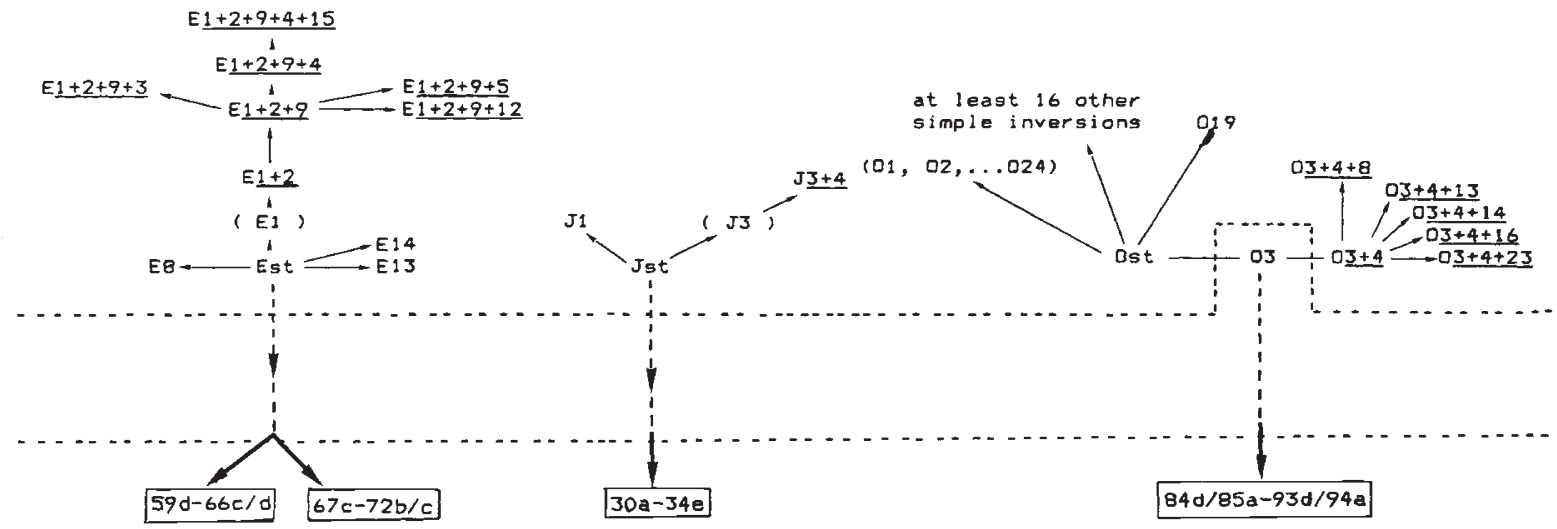

data provided by the other four chromosomes.

of polymorphisms which would lead to several fixations or to fixations in a reverse order from the temporal order of the generation of these inversions. These assumptions will not be discussed here, since they have been examined in detail by Krimbas and Powell (1990).

The seriation proposed for the three species based on data of chromosome $\mathrm{A}$ is concordant with that derived from data on overlapping inversions of chromosome $\mathrm{O}$ as explained already in the Introduction. The study of the other three rod shaped autosomes (the species also possess a pair of dot chromosomes), namely $\mathrm{U}, \mathrm{E}$ and $\mathrm{J}$, does not provide further qualitative data for ordering the species in a series through overlapping inversions. However, it is possible to include in parallel the evolution of these chromosomes too in the scheme of the phylogenetic seriation of the three species, as depicted in fig. 8. Not only do they look compatible but they also indicate that $D$. guanche differs much more from $D$. madeirensis than this species from $D$. subobscura.

These "relations" are concordant with the strength of the reproductive barrier observed among these species. In nature this barrier is quite effective, in the laboratory in forced conditions, as already mentioned in the Results section, hybrids can be obtained only between $D$. subobscura and $D$. madeirensis (in both ways, only females are fertile), and between $D$. madeirensis and $D$. guanche (only one way, both sexes are sterile) but not between $D$. subobscura and $D$. guanche. This good concordance between chromosomal data and the strength of the reproductive barrier is further evidence for the correctness of the phylogenetic relationships presented in this study.

Acknowledgement We would like to thank Dr M. Khadem for making the crosses between $D$. madeirensis and the Finnish strain of $D$. subobscura, and Mrs G. Kolia for maintaining the strains. We would like also to thank A. Shlumberger for encouragement and support by the Fondation Les Treilles.

\section{REFERENCES}

JUNGEN, H. 1968. Inversionspolymorphismus in tunesischen Populationen von Drosophila subobscura Collin. Arch. Julius Klaus-Stiftung 43, 52-57.

KRIMBAS, C. B. AND LOUKAS, M. 1984. Evolution of the obscura group of Drosophila species. I. Salivary chromosomes and quantitative characters in $D$. subobscura and two closely related species. Heredity $53,469-482$.

KRIMBAS, C. B. AND POWELL, J. R. 1990. Introduction. In Krimbas, C. B. and Powell, J. R. (eds) Inversion Polymorphism in Drosophila, CRC Press, Boca Raton, Florida. (In press).

KUNZE-MUHL, E. AND MULLER, E. 1958. Weitere Untersuchungen über die chromosomale Struktur und naturlichen Strukturtypen von Drosophila subobscura. Chromosoma 9, 559-570.

MOLTO, M., DE FRUTOS, R. AND MARTINEZ-SEBASTIAN, M. J. 1987. The banding pattern of polytene chromosomes of $D$. guanche compared with that of D. subobscura. Genetica 75, 55-70.

MOLTO, M. AND MARTINEZ-SEbASTIAN, M. J. 1986. Gene arrangements in polytene chromosomes of Drosophila guanche differing from standard arrangements in Drosophila subobscura. Dros. Inform. Servic 63, 97-98.

STURTEVANT, A. H. AND DOBZHANSKY, TH. 1936. Inversions in the third chromosome of wild races of Drosophila pseudoobscura and their use in the study of the history of the species. Proc. Natl Acad. Sci. USA, 22, 448-450. 